\title{
Benefits of effective hospital services for elderly people
}

\author{
JOHN MITCHELL, KALMAN KAFETZ, BRIAN ROSSITER
}

\begin{abstract}
An age related hospital service for elderly people was set up in Waltham Forest Health Authority to provide acute medical care when needed. Despite a reduction in the allocation of funds over the years 1982-4 the health authority increased the number of district general hospital beds available for elderly patients and improved home nursing services. The outcomes of the changes made were assessed against the aims of the service by using data from the Hospital Activity Analysis, SH3 returns, government population estimates, and yearly figures collected in our department.

It is concluded that introducing an age related service in our health authority has benefited people aged over 65 .
\end{abstract}

\section{Introduction}

The health authorities in the United Kingdom that have successfully provided hospital services for elderly people have shown that "it is the high number of District General Hospital (DGH) beds available to the elderly which enables a successful medical service to be provided." The "age related" service in $\mathrm{Hull}^{23}$ and the "integrated services" in Newcastle ${ }^{4}$ are examples of how such services may be developed. A note of despair, however, has crept into published discussions of hospital services for elderly people. Andrews and Brocklehurst suggested that demographic projections show that many more hospital beds for elderly people are necessary, ${ }^{5}$ and Coid and Crome thought it was impossible to make district general hospital beds available for elderly people in a health authority that is suffering financial cuts. ${ }^{6}$

We report how a hospital service for elderly people that is based on the age related model was set up in Waltham Forest Health Authority. The aim of our department was to ensure that effective acute medical care was provided when needed. In addition, changes introduced by the health authority saved revenue and capital, which were used to increase the number of beds for elderly people at the district general hospital and to improve home nursing services. We assess the outcome of these changes against the aims of the service and discuss the financial consequences.

\section{Background}

The health district in north east London is coterminous with the London Borough of Waltham Forest. Waltham Forest Health

\footnotetext{
Department of Medicine for Elderly People, Whipps Cross Hospital, London E11 1NR

JOHN MITCHELL, MB, MRCP, consultant physician

KALMAN KAFETZ, BSC, MRCP, consultant physician

BRIAN ROSSITER, MB, MRCP, consultant physician

Correspondence to: Dr Mitchell.
}

Authority also provides hospital services for elderly people in Wanstead and Woodford, which are in the adjacent London Borough of Redbridge. The total population served was 276000 in 1981 and is expected to fall marginally by 1991 . In 198147000 people were aged 65 years and over. This is expected to fall to 41000 by 1991 . The number of people aged 75 and over, however, is expected to rise from 18400 to 19400 by 1991, making up over $7 \%$ of the total population (appendix). In the early 1980s the district health authority was under severe financial pressure, its revenue allocation being reduced by $16 \mathrm{~m}$ ( $11 \%$ of its total yearly allocation) over the three years 1982-4. This was primarily due to the implementation of the Resource Allocation Working Party recommendations.

Before 1983 our department functioned traditionally. There were 404 beds ( 49 on the district general hospital site) and fewer than 900 deaths and discharges a year (fig 1). The waiting list for admission fluctuated between 40 and 60 people waiting at home for a bed and similar numbers awaiting transfer from another specialty. In 1980

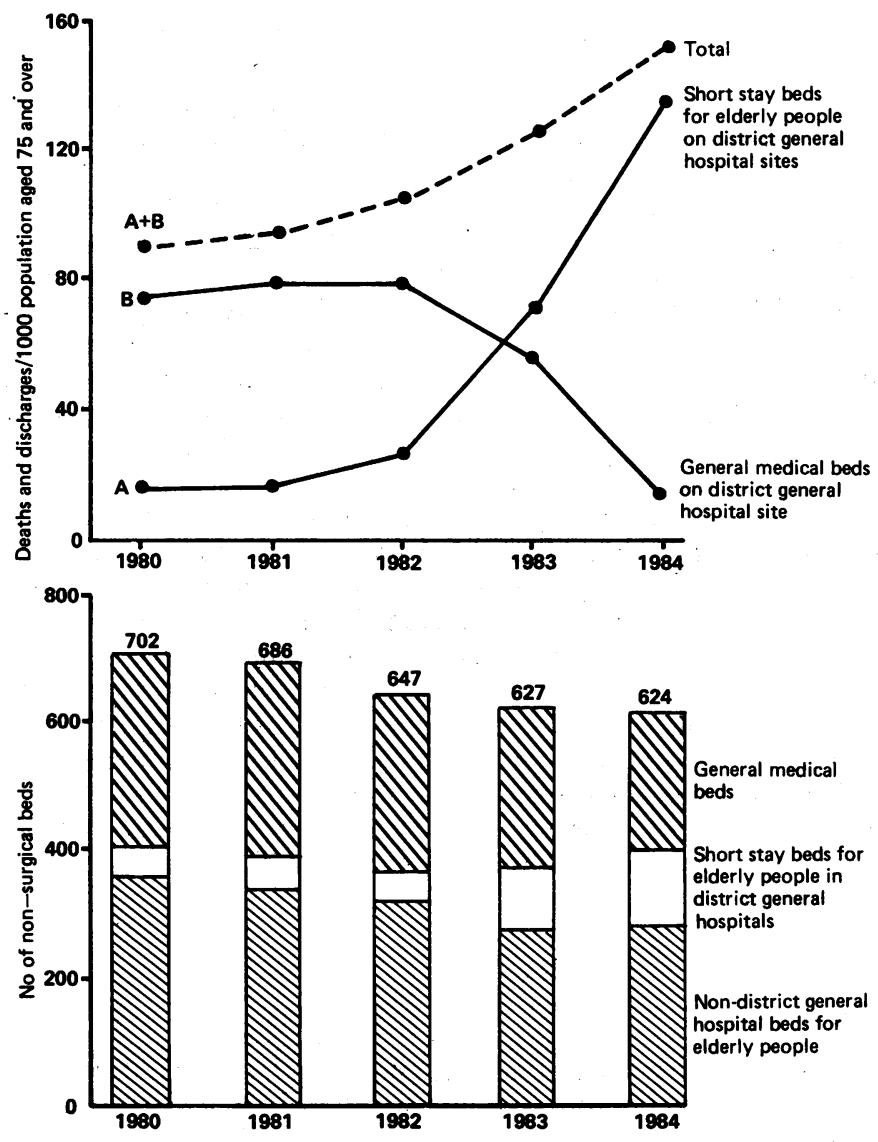

FIG 1-The number of deaths and discharges per thousand population aged 75 and over of the catchment area (the utilisation rate) from 1980 to 1984 
we proposed to develop a service to $(i)$ make more beds available at the district general hospital for immediate admission of elderly patients for acute medical problems; (ii) eliminate waiting lists; (iii) persuade doctors and other professional staff of the needs of elderly people for acute medical care; $(i v)$ discharge elderly people when the benefits of being in hospital ceased; $(v)$ reduce the demand for institutionalised residential care; $(v i)$ relieve the pressure on short stay medical beds. The other services for elderly people in the area are summarised in the appendix.

\section{Developing the service}

We defined an age related service as that in which any person who required non-surgical acute admission and who was aged 75 or over would be admitted into a bed in our department. As for admission to other specialties, the initial assessment is carried out in the accident and emergency department before a patient is transferred to the ward: there is no catchment area restriction for acute cases. Because of the relatively small number of district general hospital beds in our department we operate a system of "progressive patient care," whereby people who require longer hospital stays are transferred to beds on other hospital sites. If our district general hospital beds are full then people aged 75 and over are admitted to general medical beds, and likewise if these beds are full younger patients are admitted to our department. There is no age criterion for non-acute referrals from general practitioners and other consultants.

We preferred this type of service to an integrated service for the following reasons:

(1) The combined consequences of morbidity and social deprivation are met with increasing frequency with age. The needs of younger elderly people (aged 65 to 74) for hospital services are similar to those of younger people, but those aged 75 and over are more likely to have specific problems owing to their age.

(2) There were low expectations, little enthusiasm, and a sense of hopelessness concerning elderly people. Offering to relieve the general medical services of the workload of elderly people would encourage the more reluctant physicians to transfer resources to our department.

(3) The health authority had $2 \cdot 8$ acute beds per 1000 population and was under great pressure to reduce this number. The redesignation of medical beds to beds for the elderly helped lower the number of short stay beds while retaining the number of beds on the district general hospital site that were available for acute cases.

(4) The increase in the number of people aged 75 and over and the decrease in the number of those aged 65 to 74 focused attention on the need to put specialised services where they are most needed.

(5) If an integrated service had been introduced the specialist skills of our department would have been spread over 11 wards at the district general hospital rather than five, and it would have been difficult to introduce and sustain a high quality of care.

(6) Age 75 was the lowest age that could be chosen because of workload. Each consultant would be responsible each year for roughly 1000 people admitted to hospital, as well as having to carry out their other duties_clinical (50 day hospital places, outpatient clinics, home visits, continuing care wards, joint work with the psychiatrists and orthopaedic surgeons and the young disabled unit) and non-clinical (management, planning, teaching, research, and collaboration with the local authorities and voluntary agencies).

Changes in beds-To achieve the required reductions in revenue the district health authority closed first a ward of 20 beds at Chingford Hospital, then it closed Lugano Convalescent Home (26 beds) and Harts Hospital ( 58 beds) - a net reduction of 104 beds for elderly people, none of which was on a district general hospital site. This was offset by a reprovision of 58 beds, 25 on the district general hospital site, and an increase of $£ 50000$ for district nursing services. In addition, 49 general medical beds at the district general hospital were redesignated as beds in our department. Thus there was an increase of 73 beds on the district general hospital site, resulting in a total of 122 (29\% of all beds in our department). In 1984 there was a total of 414 beds in the health authority, 9.1 beds per 1000 people aged 65 and over and 20.9 beds per 1000 people aged 75 and over; of these, $2 \cdot 7$ beds per 1000 aged 65 and over and $6 \cdot 1$ beds per 1000 aged 75 and over were on the district general hospital site. (These figures are from SH3 data for 1982 and 1984 and from the Office of Population Censuses and Surveys population estimates.)

Changes in staffing-Because of the increased number of beds on the district general hospital site a third consultant was appointed rather than replace an associate specialist; nine clinical assistant sessions were funded; and two additional senior house officers were appointed, making a total of seven. The senior registrar and two registrar posts were to continue. Each consultant was responsible for roughly 140 hospital beds, of which 40 would be on the district general hospital site, and shared responsibility for the day hospital (appendix). The redesignation of two general medical wards at the district general hospital required an increase in trained nurses to compensate for the loss of recognition as medical training wards by the English National Board. Nurse staffing was also increased for the original 49 beds at the district general hospital. No further staff were appointed.

\section{Outcome}

District general hospital beds in our department-The number of deaths and discharges from all beds in our department rose from 948 in 1980 to 3282 in 1984, corrected for transfers between hospitals. This increase was entirely due to the throughput in beds on the district general hospital site-that is, the average number of deaths and discharges per available bed each year-where deaths and discharges rose from 380 in 1980 to 2853 in 1984: of these 2853 discharges, $70 \%$ were discharged home, $8 \%$ required transfer to a non-district general hospital bed in our department, $3 \%$ were transferred to another specialty, and $19 \%$ died during the initial admission. The number of people aged 75 and over per 1000 catchment who were admitted to a non-surgical district general hospital bed increased by $70 \%$ from 91 in 1980 to 155 in 1984 . The improved access, however, was limited to district general hospital beds in our department (fig 1). Length of stay was reduced to $12 \cdot 6$ days and turnover interval to $2 \cdot 2$ days, with an increased bed

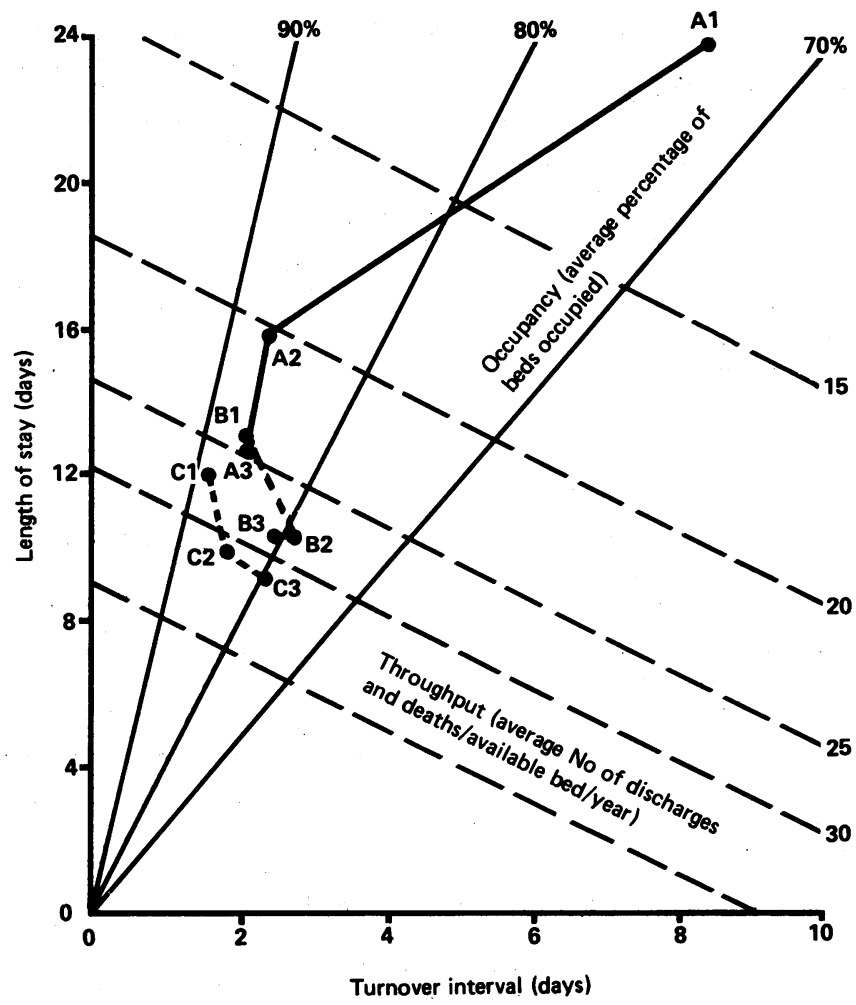

FIG 2-The change in performance indicators (see text) of district general hospital beds for elderly people (A), all medical beds in the district (B), and medical beds on the district general hospital site (C) in 1982 (1), 1983 (2), and 1984 (3). 
occupancy of $85 \%$ and throughput of 24.7 people per bed a year by 1984 (fig 2). ${ }^{78}$

General medical beds-During this transition there was an overall reduction in general medical beds of $89(30 \%)$, and the number of deaths and discharges from those beds fell from 6608 in 1980 to 5391 in $1984(18 \%)$. There was an increased throughput and a shorter length of stay, indicating a reduction in the numbers of patients with complex medical and social needs. Moreover, occupancy fell and turnover interval lengthened, suggesting that there was less pressure on the use of the beds (fig 2).

All acute non-surgical beds (our department and general medicine)The combined numbers of deaths and discharges from all acute non-surgical specialties rose by $13 \%$, from 7556 in 1980 to 8673 in 1984, while the numbers of deaths and discharges of all people aged 75 and over from the district general hospital site rose by $89 \%$, from 1627 in 1980 to 3083 in 1984 . After the policy was introduced the number of people aged 65 to 74 who were discharged from hospital fell more than the reduction in population would explain. Since 1984 , however, the numbers have risen.

Non-district general hospital beds in our department-The occupancy of non-district general hospital beds fell from $93 \%$ in 1980 to $81 \%$ in 1984 . This suggests that there is less need for residential care in hospital, though the following may have contributed: (i) the local authority introduced a home care programme that has enabled more severely physically disabled people, who are considered to be too disabled for part III homes, to live at home rather than in hospital; (ii) the number of places in private and voluntary homes has increased from 97 in 1981 to 164 in 1985; (iii) the provision of continuing care in hospital, which replaced Harts Hospital, is some distance away, and the uptake has been less than expected, giving a spuriously low non-district general hospital occupancy.

Waiting lists-By 1983 there was no longer a waiting list for admission from the community. This was achieved before the increase in district general hospital beds. Since 1984 there has been no delay in the transfer from other specialties of elderly people who live in the catchment area and would benefit from the services of our department, as shown by the census data collected yearly in January (table I).

TABLE I-One day census in our department of numbers of people in general medical beds aged 65 to 74 and aged 75 and over who were in hospital for over eight weeks and over 12 weeks in 1983, 1984, and 1985

\begin{tabular}{|c|c|c|c|c|c|c|}
\hline & \multicolumn{6}{|c|}{ Number of patients in hospital } \\
\hline & \multicolumn{2}{|c|}{1983} & \multicolumn{2}{|c|}{1984} & \multicolumn{2}{|c|}{1985} \\
\hline & $\begin{array}{c}\text { Over } \\
8 \text { weeks }\end{array}$ & $\begin{array}{c}\text { Over } \\
12 \text { weeks }\end{array}$ & $\begin{array}{c}\text { Over } \\
8 \text { weeks }\end{array}$ & $\begin{array}{c}\text { Over } \\
12 \text { weeks }\end{array}$ & $\begin{array}{c}\text { Over } \\
8 \text { weeks }\end{array}$ & $\begin{array}{c}\text { Over } \\
12 \text { weeks }\end{array}$ \\
\hline $\begin{array}{l}\text { Aged } 65-74 \\
\text { Aged } 75 \text { and over }\end{array}$ & $\begin{array}{l}13 \\
22\end{array}$ & $\begin{array}{l}0 \\
4\end{array}$ & $\begin{array}{r}10 \\
5\end{array}$ & $\begin{array}{l}2 \\
1\end{array}$ & $\begin{array}{r}13 \\
5\end{array}$ & $\begin{array}{l}1 \\
0\end{array}$ \\
\hline
\end{tabular}

TABLE II-Costs and savings (in parentheses) of developing services for elderly people in Waltham Forest Health Authority 1982-4. (Figures are rounded to the nearest $£ 1000$ and are at 1983 prices)

\begin{tabular}{|c|c|c|}
\hline & $\mathfrak{£ 0 0 0}$ & \\
\hline $\begin{array}{l}\text { Closure of Harts Hospital } \\
\text { Closure of Lugano } \\
\text { Closure of non-district general hospital ward at Chingford Hospital }\end{array}$ & $\begin{array}{r}(1100) \\
(120) \\
(150)\end{array}$ & \\
\hline Total & (1370) & (1370) \\
\hline $\begin{array}{l}\text { Redesignate } 49 \text { general medical beds to } 49 \text { beds for elderly people on district } \\
\text { general hospital site }\end{array}$ & 155 & \\
\hline $\begin{array}{l}\text { Reprovide } 25 \text { beds on district general hospital site from closure of Harts } \\
\text { Additional costs of reproviding } 33 \text { beds on non-district general hospital site }\end{array}$ & 303 & \\
\hline from closure of Harts & 55 & \\
\hline Increase district nursing services & 50 & \\
\hline Increase nurse staffing to existing district general hospital beds & 58 & \\
\hline Increase nurse staffing to non-district general hospital beds & 70 & \\
\hline Increase medical staffing levels & 48 & 739 \\
\hline Total & & (631) \\
\hline
\end{tabular}

Readmission - We have no data on readmission rates. Victor and Vetter described some of the difficulties in measuring and interpreting these. ${ }^{9}$ From one small survey in 1984 in Waltham Forest it was concluded that $11 \%$ of patients discharged from our department were readmitted within one month, but the reason for the readmission was not assessed. ${ }^{10}$

Revenue and capital-The savings from introducing the service were $£ 631000$ at 1985 prices (table II). Of these, $£ 412000$ came from the change of use of general medical beds and $\$ 219000$ from closing beds in our department. These savings were realised even after the increases in nursing and medical staff. In addition, Lugano Convalescent Home has been sold for $£ 375000$, and the Harts Hospital site has an estimated value of over $£ 10 \mathrm{~m}$ at 1987 prices.

\section{Discussion}

The numbers of deaths and discharges of people aged 75 and over to all acute non-surgical beds increased by $89 \%$ after an age related service was introduced. This increase is probably due to a combination of previously undetected medical needs ${ }^{11}$ which are now being met: effective hospital care for a greater number of apparent "social problems" who in fact had unrecognised and treatable illness ${ }^{12}$ and a historical high dependence in east London on accident and emergency departments rather than on primary health care services.

These results confirm the importance of beds on the district general hospital site ${ }^{\prime}$; before 1983 , despite improvements in medical staffing, an age related admission policy, and a good rehabilitation service there was only minimal improvement in performance. Only when a critical number of beds was achieved on the district general hospital site were we able to offer a better service to elderly people.

The service functions with relatively few beds on the district general hospital site: 122 . Grimley Evans suggested that $5 \cdot 5$ district general hospital beds per 1000 population aged 65 and over would be required to operate successfully an age related service for people aged 75 and over, ${ }^{13}$ whereas our service functions with only $2 \cdot 7$ beds per 1000 people over 65 . Grimley Evans has also pointed out that the increasing number of people aged 75 and over will have an important impact on hospital services. ${ }^{14}$ To this end an alternative, more sensitive norm of 23.5 total hospital beds per 1000 population aged 75 and over was proposed by the regional health authority. ${ }^{15}$ In Waltham Forest there were only 20.9 beds in 1984, a deficit of 68 beds for elderly people in the district compared with the region's target.

The number of our district general hospital beds should be increased further, thus reducing the need to transfer patients who need longer rehabilitation and allowing for the inevitable delays in transferring patients from outside the catchment area $(7 \%$ of all admissions) back to their host service. In the large metropolitan conurbations such as London there will inevitably be "cross boundary" flow for short stay admissions of patients of all ages, and this should be taken into account when services are planned and developed.

It would be possible to admit, treat, and rehabilitate most patients aged 75 and over, as well as some younger people with age related illness, if the number of beds on the district general hospital site were increased to 4.5 per 1000 people aged 65 and over or 10 per 1000 people aged 75 and over. Planning for continuing care is more complex because the need will depend on the availability of acute and domiciliary services and other forms of residential places. Some National Health Service provision is likely to be necessary for the foreseeable future, and this should consist of small units in local communities where the staff can develop special skills that may not be available on a short stay ward.

"Bed norms" are often used erroneously to reflect either the quality or the quantity of service provided for elderly people, but more important is the use to which those beds are put. Our experience suggests that an effective service can be provided with bed norms that have previously been regarded as inadequate.

The debate on the relative merits of age related and integrated services continues. In a district health authority which is losing 
revenue but has a comparatively generous total provision of district general hospital beds (as in our area) an age related system allowed us to develop and provide an effective service for the elderly population. It relies on collaboration between medical and surgical specialties so that elderly people can benefit from the range of skills available. On the other hand, in a health authority where local short stay beds are at a premium an integrated service will make more district general hospital beds available for elderly people, allowing them equal access to the specialist services that younger people enjoy. ${ }^{4}$ Irvine has pointed out that a quarter of all general medical beds would have to be transferred if a uniform age related service was implemented nationally: this would be inappropriate in some districts. ${ }^{16}$

Services for elderly people have been underfunded, and this has improved only a little ${ }^{17} 18$ since the publication of Priorities for Health and Personal Social Services in England.$^{19}$ The inefficient use of short stay hospital facilities, which fail to treat and discharge elderly people, and continuing care hospitals, which "induce" and "structure" dependency, ${ }^{20}$ will only exacerbate underfunding. In Waltham Forest the improvements in services for elderly people had to be introduced because of reductions in resources and were achieved with savings in revenue and with capital benefit.

Figure 3 illustrates the process of change in Waltham Forest.

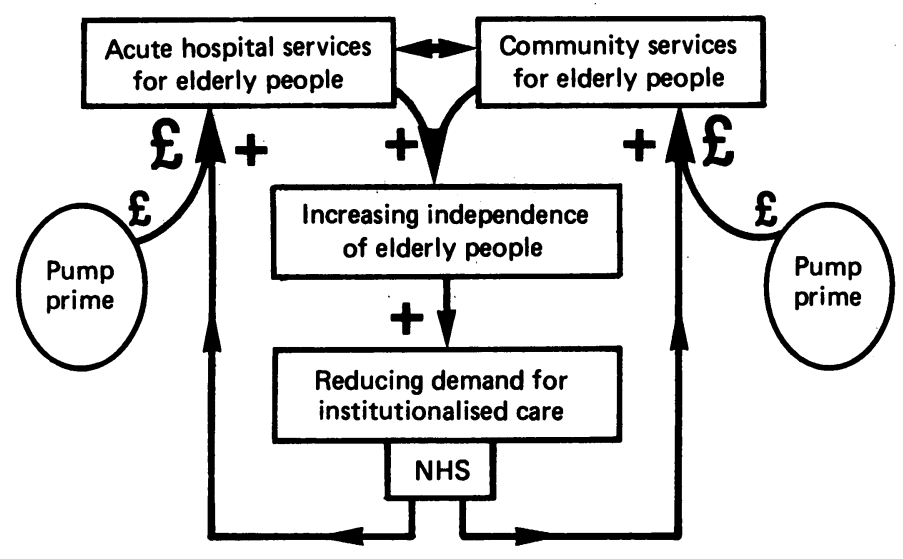

FIG 3-The changing pattern of service provision in Waltham Forest Health Authority.

Over $95 \%$ of elderly people live in their own homes, some relying on services from statutory and non-statutory agencies. ${ }^{21}$ Community services support profoundly disabled people but cannot manage patients with acute illness. The district general hospital services recognise and respect the special needs of elderly people (an essential community resource), without which community care falters and fails.

By "pump priming" hospital services (redesignating general medical beds) and community services (joint finance and local authority resources put into home care), more elderly people are able to live in their own homes, thus maintaining their independence, raising their aspirations, enlightening friends and relatives and other professionals, and reducing the demand for permanent residential care, particularly in the NHS.

To argue now for a global increase in the number of hospital beds to cope with demographic changes negates many of the developments that have occurred. A properly resourced hospital service for elderly people, based on the principles used in Waltham Forest and elucidated by Horrocks, ${ }^{22}$ is only one component of the total service that elderly people should expect. These services, however, concentrate on redressing the effects of ill health and disability rather than improving health. Rather, resources that are made available should promote the physical, mental, and social wellbeing ${ }^{23}$ of elderly people. This requires a concerted effort to reduce the effects of poverty ${ }^{24}$ and minimise the "ageism" so prevalent in society, while a range of services are provided which respect the rights of elderly people to self determination and interdependence.
We thank Angela Ward and Mike Woods for collecting data; John Scampion for financial information; Sheila Adam and an unknown referee for comments on previous drafts; Pat Norton for typing many scripts; and, most important, the elderly people who were unknowingly the major contributors to this paper.

\section{Appendix}

(1) Population of total catchment area (Waltham Forest, Wanstead, and Woodford). Figures in thousands (percentages in parentheses)

\begin{tabular}{lccc}
\hline & 1981 & 1985 & 1991 \\
\hline Aged 65-74 years & $28 \cdot 8(10 \cdot 4)$ & $24 \cdot 5(8 \cdot 9)$ & $22 \cdot 4(8 \cdot 2)$ \\
$75+$ years & $18 \cdot 4(6 \cdot 7)$ & $20 \cdot 5(7 \cdot 5)$ & $19 \cdot 4(7 \cdot 1)$ \\
\hline Total & $276 \cdot 3(100)$ & $274 \cdot 6(100)$ & $273 \cdot 4(100)$ \\
\hline Office of Population Censuses and Surveys population estimates.
\end{tabular}

(2) Population of Waltham Forest Health Authority in 1985 in thousands (percentages in parentheses)

\begin{tabular}{ll}
\hline $\begin{array}{l}\text { Aged } \\
65-75 \text { years }\end{array}$ & $18 \cdot 9(11 \cdot 4)$ \\
$75+$ years & $16(7 \cdot 4)$ \\
\hline \multicolumn{1}{c}{ Total } & $216 \cdot 2(100)$ \\
\hline $\begin{array}{l}\text { Office of Population Censuses and } \\
\text { Surveys population estimates }\end{array}$
\end{tabular}

(3) Number of beds in the department of psychiatry of old age for Waltham Forest Health Authority

(4) Number of day hospital places in Waltham Forest Health Authority for entire catchment area

(5) Number of places in local authority residential homes (part III) in Waltham Forest in 1984

(6) Number of people in private and voluntary homes supported by the London Borough of Waltham Forest

(7) Number of places in private and voluntary (rest) homes in Waltham Forest in 1984

(8) Number of places in purpose built (sheltered) housing in Waltham Forest in 1984

(9) Number of private nursing homes in Waltham Forest

\section{References}

1 Evans JG. Institutional care. In: Arie T, ed. Health care of the elderly. London: Croom Helm, 1981:176-93.

2 Bagnall WE, Datta SR, Knox J. Geriatric medicine in Hull: a.comprehensive service. $\mathrm{Br} \mathrm{Med} \mathcal{F}$ 1977;ii:102-4

3 Horrocks $P$. The case for geriatric medicine as an age-related speciality. In: Isaacs B, ed. Recent advances in geriatric medicine. Vol 2. London: Churchill Livingstone, 1982:259-77.

4 Evans JG. Integration of geriatric with general medical services in Newcastle. Lancet 1983; 1430-3.

5 Andrews K, Brocklehurst JC. The implications of demographic change on resource allocation. J R Coll Physicians Lond 1985;19:109-11.

6 Coid J, Crome P. Bed blocking in Bromley. Br Med f 1986;292:1253-6.

7 Barber B, Johnson D. The presentation of acute hospital in-patient statistics. Hospital and Health Services Review 1975;69:11-4.

8 Yates J. Hospital beds. London: Heinemann, 1982:105-16.

9 Victor C, Vetter NJ. The early readmission of the elderly to hospital. Age. Ageing 1985;14:37-42.

10 Morrison L, Simonen O. Field service attachment. London: London School of Hygiene and Tropical Medicine, 1984.

11 Williamson J, Stokoe IH, Gray S, Fisher M, Smith A. Old people at home, their unreported needs. Lancet 1964;i:1117-20.

12 Boyd RV. What is a "social problem" in geriatrics? In: Arie T, ed, Health care of the elderly. London: Croom Helm, 1981:143-57.

13 Evans JG. Care of the elderly in a defined community. In: Hodkinson HM, Graham J, eds. Effective geriatric medicine. London: Department of Health and Social Security, 1983:21-6.

14 Evans JG. The provision of care for the elderly. London: Churchill Livingstone, 1981:8-13.

15 North East Thames Regional Health Authority. Regional strategic plan 1984-1993. London: NETRHA, 1984:81-94.

16 Irvine RF. Geriatric medicine and general internal medicine. $f R$ Coll Physicians Lond 1984;18: 21-4.

17 McCarthy M. Cutting the cake: government spending plans for 1986-9. BrMed 1 1986;292:840-2.

18 Mikin D, Hughes B. The elderly and the health service. In: Phillipson C, Walker C, eds. Ageing and Social Policy. Aldershot: Gower, 1986:163-83.

19 Department of Health and Social Security. Prionities for health and personal social services in England. London: HMSO, 1976.

20 Townsend P. The structured dependency of the elderly. Ageing and Society 1981;1:5-28.

21 Clarke M, Hughes OA, Dodd KH, et al. The elderly in residential care. Patients of disability. Health Trends 1979;11:17.

22 Horrocks $P$. The components of a comprehensive district health service for elderly people-a personal view! Age Ageing 1986;15:321-432.

23 Anonymous. Report of the international conference on primary health care, Alma Ata, USSR. Geneva: World Health Organisation, 1978.

24 Townsend P. Poverny in the United Kingdom. Harmondsworth: Pelican, 1979:784-822.

(Accepted 1 May 1987) 